\section{Benefits of heat re-acclimation in the lead-up to the Tokyo Olympics}

\author{
Sebastien Racinais (10,1' Julien D Périard (i) ${ }^{2}$
}

As presented in the first editorial from this series, the Tokyo Olympics are expected to be the hottest in modern history. ${ }^{1}$ While the postponing from 2020 to 2021 will not change the period of the year, it will allow more time for athletes to plan for multiple heat acclimation camps. Indeed, heat acclimation is the most important countermeasure athletes can adopt to protect their health and enhance performance. ${ }^{2}$ Heat acclimation develops following repeated training in hot conditions in response to marked increases in core and skin temperature, skin blood flow and sweat rate. $^{2}$ It is commonly accepted that daily training in the heat for 60-90 min for 2 weeks allows for adaptations to occur, including plasma volume expansion and enhanced heat dissipation. ${ }^{3}$ These adaptations contribute to lower the cardiovascular response associated with exercising in the heat and thus improve performance. ${ }^{3}$ The time course of these adaptations is relatively rapid with a large fraction of adaptations occurring during the first week of training in the heat and the remaining adaptations developing during the second week, ${ }^{4}$ although a large interindividual variability exists in the magnitude and time frame of the adaptive process. ${ }^{5}$ tively well understood, a common question from coaching and medical teams is how to integrate heat acclimation within the training and taper programme of elite athletes. Laboratory and field studies have shown that performance is increased after 1 or 2 weeks of training in the heat ${ }^{6}$; however, it may be impractical for athletes to dedicate 2 weeks to training daily in the heat immediately before a major event. Indeed, the thermal and cardiovascular strain necessary to induce the required adaptations may

${ }^{1}$ Research Education Centre, ASPETAR-Qatar Orthopaedic and Sports Medicine Hospital, Doha, Qatar ${ }^{2}$ Research Institute for Sport and Exercise, University of Canberra, Canberra, Australian Capital Territory, Australia

Correspondence to Dr Sebastien Racinais, Research Education Centre, ASPETAR - Qatar Orthopaedic and Sports Medicine Hospital, Doha 29222, Qatar; sebastien.racinais@aspetar.com
While the above principles are rela- interfere with the workload programmed within the training schedule, as well as impede recovery during the taper period, or disrupt travel arrangements. Notwithstanding, two points are important to clarify. First, the daily heat exposures (which can be passive) required to induce heat acclimation are relatively short, which allow athletes the opportunity to train and rest in cool environments. Second, the decay of acclimation appears to be slower than its induction, ${ }^{4}$ which lends itself to be performed in advanced of competition and supplemented by a short 'top-up' prior to competition. ${ }^{7}$

The approach of heat acclimating in advance is further supported by the rebound effect of re-acclimation, wherein a second acclimation period within a month of the initial one allows for faster and in some cases more profound adaptations. $^{4}$ For example, Weller et $a l^{8}$ showed that following an initial 10-day acclimation period, 2 and 4 days of re-acclimation after 12 and 26 days without heat exposure (ie, decay) were sufficient to regain a similar acclimation status (figure 1). A recent meta-analyses also estimated that $\sim 35 \%$ of the heart rate, $\sim 30 \%$ of the sweat rate and $\sim 36 \%$ of the core temperature adaptations are lost in the 2 weeks following heat acclimation. ${ }^{4}$ However, regular exercise-heat exposure during this period decreases the rate of decay. Passive heat exposure may also be used during this period to accommodate travel and/or taper requirements, all the while providing the stimulus to maintain adaptation. A re-acclimation period of $2^{9}$ to $5^{10}$ days closer to competition would then be sufficient to regain adaptation, with an extended re-acclimation period potentially allowing for further adaptations to develop. ${ }^{11}$

In summary, it is imperative to heat acclimate before participating in prolonged events in the heat to protect the health and optimise the performance of athletes. ${ }^{2}$ Thus, an athlete preparing for Tokyo or any other competition in hot/humid ambient conditions may wish to plan an initial heat acclimation camp 4 weeks before the Olympics and subsequently maintain or minimise the decay in adaptations with regular exercise or passive heat exposure until travelling (eg, once every 3 days). This would allow a fast re-acclimation on arrival at the competition venue.

Twitter Sebastien Racinais @ephysiol and Julien D Périard @DrJPeriard

Acknowledgements This editorial was inspired by discussions with numerous coaches across the year.

Contributors SR and JP wrote this editorial.

Funding The authors have not declared a specific grant for this research from any funding agency in the public, commercial or not-for-profit sectors.

Competing interests None declared.

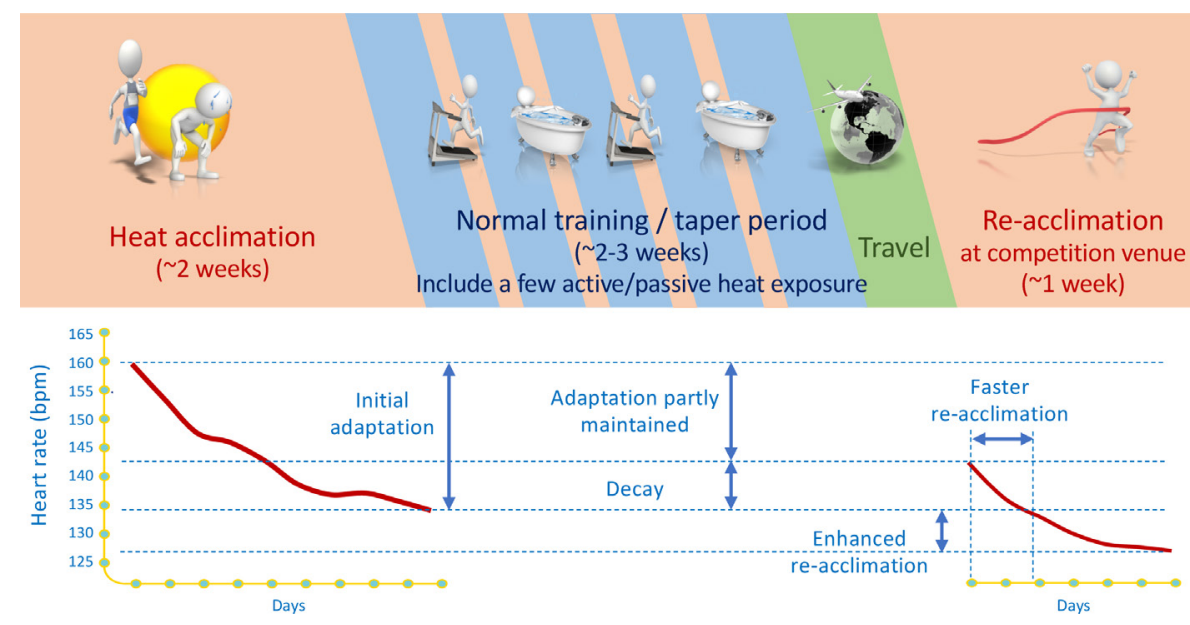

Figure 1 Potential heat acclimation periodisation. Athletes can undergo a heat acclimation regimen several weeks in advance of competition, maintain some of the adaptations through exercise and periodic post-exercise hot water immersion until travelling, and then re-acclimate with 2-3 sessions after arriving at the competition venue. The bottom panel provides an example of the time frame and magnitude of adaptation in heart rate during exercise in the heat when conducting an initial 10-day heat acclimation camp and a subsequent 5 or 7 days of re-acclimation 12 and 26 days later, respectively. Redrawn with permission from Weller et al. ${ }^{8}$ 
Patient consent for publication Not required.

Provenance and peer review Not commissioned; externally peer reviewed.

(c) Author(s) (or their employer(s)) 2020. No commercial re-use. See rights and permissions. Published by BMJ.

\section{A) Check for updates}

To cite Racinais S, Périard JD. Br J Sports Med 2020;54:945-948.

Accepted 1 April 2020

Published Online First 10 April 2020

Br J Sports Med 2020;54:945-948.

doi:10.1136/bjsports-2020-102299

\section{ORCID iDs}

Sebastien Racinais http://orcid.org/0000-0003-0348-

4744

Julien D Périard http://orcid.org/0000-0002-6266-4246

\section{REFERENCES}

1 Racinais S, Ihsan M. Why should I test my athletes in the heat several months before Tokyo 2020? Br J Sports Med. doi:10.1136/bjsports-2020-102082. [Epub ahead of print: $29 \mathrm{Feb} 2020]$.

2 Racinais S, Alonso JM, Coutts AJ, et al. Consensus recommendations on training and competing in the heat. Br J Sports Med 2015;49:1164-73.

3 Périard JD, Racinais S, Sawka MN. Adaptations and mechanisms of human heat acclimation: applications for competitive athletes and sports. Scand J Med Sci Sports 2015;25 Suppl 1:20-38.

4 Daanen HAM, Racinais S, Périard JD. Heat acclimation decay and re-induction: a systematic review and metaanalysis. Sports Med 2018;48:409-30.

5 Racinais S, Mohr M, Buchheit M, et al. Individual responses to short-term heat acclimatisation as predictors of football performance in a hot, dry environment. Br J Sports Med 2012;46:810-5.
6 Racinais S, Périard JD, Karlsen A, et al. Effect of heat and heat acclimatization on cycling time trial performance and pacing. Med Sci Sports Exerc 2015;47:601-6.

7 Saunders PU, Garvican-Lewis LA, Chapman RF, et al. Special environments: altitude and heat. Int I Sport Nutr Exerc Metab 2019;29:210-9.

8 Weller AS, Linnane DM, Jonkman AG, et al. Quantification of the decay and re-induction of heat acclimation in dry-heat following 12 and 26 days without exposure to heat stress. Eur J Appl Physiol 2007;102:57-66.

9 Casadio JR, Kilding AE, Cotter JD, et al. From lab to real world: heat acclimation considerations for elite athletes. Sports Med 2017;47:1467-76.

10 Ashley CD, Ferron J, Bernard TE. Loss of heat acclimation and time to re-establish acclimation. J Occup Environ Hyg 2015;12:302-8.

11 Saat M, Sirisinghe RG, Singh R, et al. Decay of heat acclimation during exercise in cold and exposure to cold environment. Eur J Appl Physiol 2005;95:313-20. 